\title{
Comprehensive review of fetal adenocarcinoma of the lung
}

This article was published in the following Dove Press journal: Lung Cancer:Targets and Therapy

\section{Luisa María Ricaurte' \\ Oscar Arrieta ${ }^{2}$ \\ Zyanya Lucia \\ Zatarain-Barrón ${ }^{2}$ \\ Andrés F Cardonal,3 \\ 'Foundation for Clinical and Applied Cancer Research - FICMAC, Bogotá, Colombia; ${ }^{2}$ Thoracic Oncology Unit, National Cancer Institute (INCan), México City, México; ${ }^{3} \mathrm{Clinical}$ and Translational Oncology Group, Institute of Oncology, Clínica del Country, Bogotá, Colombia}

Correspondence: Andrés F Cardona Foundation for Clinical and Applied Cancer Research - FICMAC, Calle II 6 No 9-72, c. 318, Bogotá II0III, Colombia

Tel +57 I 6190052

Fax +57 I 6190053

Email andres.cardona@clinicadelcountry. com

\begin{abstract}
Fetal adenocarcinoma of the lung (FLAC) is a rare tumor. It accounts for $\sim 0.1 \%-0.5 \%$ of all pulmonary neoplasms. Due to its rarity, much of the world literature regarding FLAC comes from case reports and case series. FLAC is an adenocarcinoma resembling developing fetal lung in its pseudoglandular stage (8-16 weeks of gestation). It is distinguishable from pulmonary blastoma (PB) because it lacks the mesenchymal component which is a hallmark finding in PB. Due to differences in histopathology and clinical course, FLAC has been further categorized into low-grade (L-FLAC) and high-grade (H-FLAC) forms. L-FLAC displays low nuclear atypia and prominent morule formation and has a pure pattern. H-FLAC typically presents with at least $50 \%$ fetal morphology, and is often associated with other conventional types of lung adenocarcinoma. FLAC expresses neuroendocrine markers and thyroid transcription factor 1 in most cases. L-FLAC has an aberrant nuclear/cytoplasmic expression of $\beta$-catenin and presents mutations in this gene. H-FLAC overexpresses $\mathrm{p} 53$. These tumors have a very low frequency of mutations in $K R A S$ and $E G F R$; it is thought that they are different from a molecular point of view to conventional lung adenocarcinomas. Approximately $25 \%-40 \%$ of patients are asymptomatic at presentation; most of them are incidental findings on chest radiographs. H-FLAC is more common in elderly male patients, with a heavy smoking history. L-FLAC tends to occur in young females. Patients with L-FLAC are usually diagnosed with stage I-II disease, while patients with H-FLAC usually present with a more advanced-stage disease. Poor prognostic factors for FLAC are thoracic lymphadenopathy, metastases at diagnosis, and tumor recurrence; however, the 10-year survival for FLAC is estimated at $75 \%$.
\end{abstract}

Keywords: lung cancer, fetal adenocarcinoma, outcomes, chemotherapy, radiotherapy, L-FLAC, H-FLAC, p53

\section{Introduction}

Fetal adenocarcinoma is a rare type of lung neoplasia. It accounts for $\sim 0.1 \%-0.5 \%$ of all pulmonary neoplasms. ${ }^{1-3}$ This tumor was first described by WG Barnard in 1945 and 1952, as a biphasic tumor of the lung comprising an epithelial component surrounded by mesenchymal stroma that resembled the fetal lung, hence naming it "embryoma of the lung. ${ }^{\prime, 5}$ In 1961, Spencer introduced the term pulmonary blastoma (PB) after studying additional cases. ${ }^{6}$ Later on, several authors reported other epithelial lung tumors that shared histological characteristics of the epithelial component present in PB, but lacked the mesenchymal component. ${ }^{7,8}$ In 1984, Kodama et al introduced the phrase "well differentiated fetal adenocarcinoma of the lung" (FLAC) to categorize these tumors. ${ }^{8}$ Finally, in 1999 the World Health Organization (WHO) classified this tumor as a variant of lung adenocarcinoma and it is now known as FLAC. The 
biphasic tumor is now part of the sarcomatoid carcinomas category and termed PB. Today, FLAC is recognized as a very uncommon lung adenocarcinoma with different pathogenesis, clinical manifestations, histopathology, and prognosis than PB. ${ }^{9-11}$ Much of the world literature regarding FLAC comes from case reports and case series. This review will describe the histopathological findings of this tumor, the genomics, diagnosis, and clinical characteristics, treatment, and outcomes. Surgical resection is the standard treatment, although adjuvant therapy with radiotherapy and chemotherapy has been reported.

\section{Pathology}

FLAC is an adenocarcinoma resembling developing fetal lung in its pseudoglandular stage (8-16 weeks of gestation). ${ }^{12-14}$ The tumor is usually solitary, well demarcated, and peripherally located although endobronchial involvement has been described. ${ }^{12,15-17}$ FLAC comprises complex, branch forming tubular glands lined by glycogen-rich, non-ciliated columnar or cuboidal cells. The cells have clear cytoplasm; large vesicular nuclei are seen in addition to supranuclear or subnuclear vacuoles. The malignant glands are densely packed and situated within loose to moderate cellular fibroblastic stroma. There is a morphologic resemblance to early secretory endometrium. ${ }^{12,14,16-20}$ Due to differences in histopathology and clinical course, FLAC has been further categorized into low-grade (L-FLAC) and high-grade (H-FLAC) forms. ${ }^{11,14}$
A study that screened 920 adenocarcinomas calculated the prevalence of FLAC to be $0.87 \%$; among these $0.32 \%$ were L-FLAC and $0.54 \%$ were H-FLAC. ${ }^{18}$

L-FLAC displays low nuclear atypia and prominent morule formation (Figure 1A). The stroma is typically loose fibromyxoid tissue with spindle cells. ${ }^{12,14,18,21}$ L-FLAC is pure in pattern. ${ }^{12}$ In contrast, H-FLAC presents typically with at least $50 \%$ fetal morphology, and is often associated with other conventional types of lung adenocarcinoma (lepidic, papillary, acinar, micropapillary, and solid patterns). Although not recognized in the last WHO classification, a hepatoid pattern defined as a solid to trabecular growth of tumor cells with eosinophilic cytoplasm and clear cell component has also been described. ${ }^{14,18,22,23}$ According to WHO, H-FLAC diagnosis is rendered when the fetal histology is predominant. Additionally, these high-grade tumors have prominent nuclear atypia, prominent nucleoli, and frequent mitosis, in addition to lacking morule formation (Figure 1B). ${ }^{12,14,18,21,23}$ Currently, L-FLAC and $\mathrm{H}-\mathrm{FLAC}$ are recognized by the WHO classification under the name of FLAC; nevertheless, some authors question whether H-FLAC is a distinct variant of lung cancer, which can present as a biphasic tumor or as pure fetal H-FLAC. ${ }^{18,23}$

The histopathological and immunohistochemical characteristics of L-FLAC and H-FLAC are summarized in Table 1.

These two categories of FLAC also show differences in their immunohistochemical profile. Both L-FLAC and H-FLAC show positivity for neuroendocrine markers

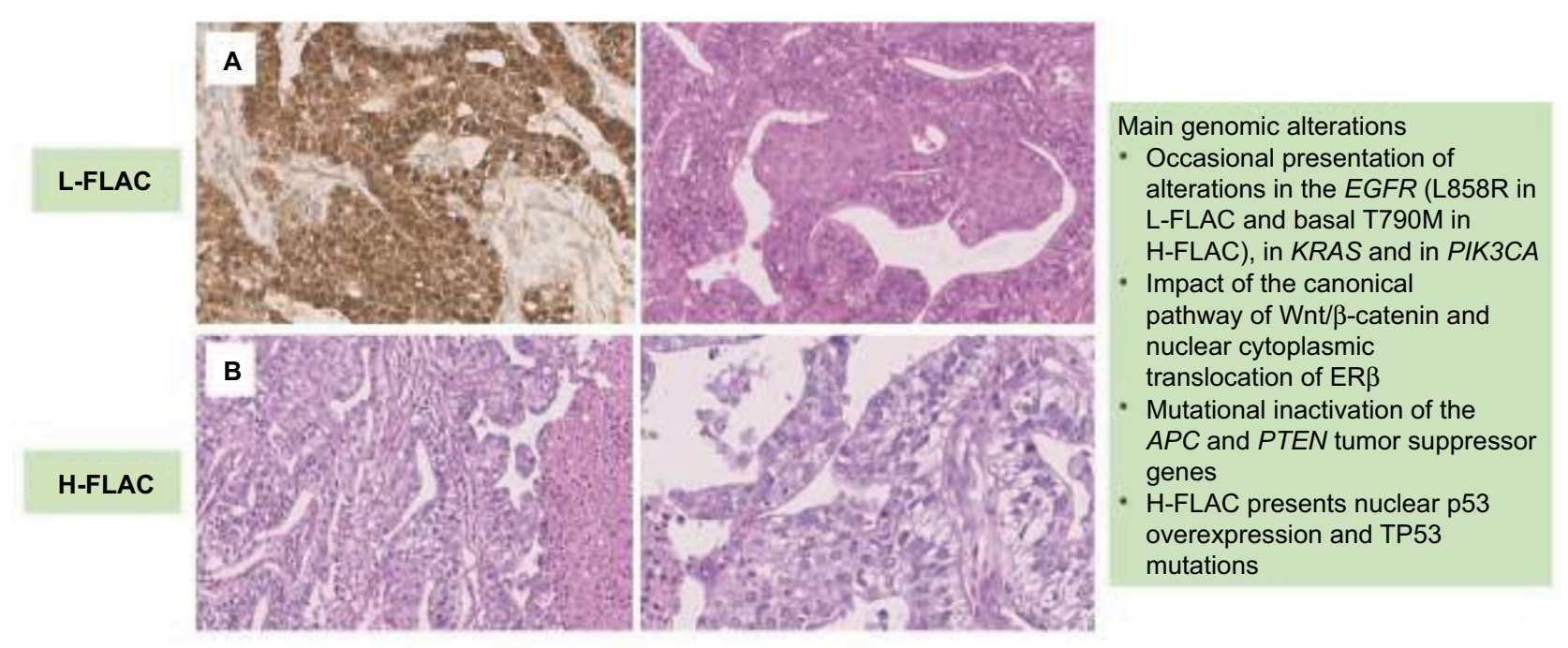

Figure I Morphological characteristics of fetal lung adenocarcinomas.

Notes: (A) Histology and immunophenotype of L-FLAC, which consists of complex glandular structures lined with glycogen-rich columnar cells, with low nuclear atypia, and morule formation. (B) H-FLAC exhibits the absence of morules, broad areas of necrosis, and complex acinar glands that consist of columnar tumor cells with supranuclear or subnuclear cytoplasmic clearing, large vesicular nuclei, prominent nucleoli.

Abbreviations: L-FLAC, low-grade fetal adenocarcinoma of the lung; H-FLAC, high-grade fetal adenocarcinoma of the lung; APC, adenomatous polyposis coli; ER $\beta$, estrogen receptor $\beta$. 
Table I Histopathological, immunohistochemical, and genomic characteristics of L-FLAC and H-FLAC

\begin{tabular}{|c|c|c|}
\hline FLAC & L-FLAC & H-FLAC \\
\hline $\begin{array}{l}\text { Morphologic resemblance to the fetal lung } \\
\text { in its pseudoglandular stage ( } 8-16 \text { weeks of } \\
\text { gestation) and to early secretory endometrium }\end{array}$ & $\begin{array}{l}\text { Low nuclear atypia and } \\
\text { prominent morule formation }\end{array}$ & $\begin{array}{l}\text { Prominent nuclear atypia, prominent nucleoli, and } \\
\text { frequent mitosis } \\
\text { Absent morule formation }\end{array}$ \\
\hline $\begin{array}{l}\text { Complex, branch forming tubular glands lined } \\
\text { by glycogen-rich, non-ciliated columnar or } \\
\text { cuboidal cells. Cells have clear cytoplasm, } \\
\text { large vesicular nuclei and supranuclear or } \\
\text { subnuclear vacuoles }\end{array}$ & Pure pattern & $\begin{array}{l}50 \% \text { Fetal morphology and often associated } \\
\text { with other conventional types of lung } \\
\text { adenocarcinoma }{ }^{\mathrm{a}, \mathrm{b}}\end{array}$ \\
\hline \multirow[t]{2}{*}{$\begin{array}{l}\text { Positivity for neuroendocrine markers } \\
\text { (chromogranin A and synaptophysin) and } \\
\text { TTF-Ic }\end{array}$} & $\begin{array}{l}\text { Aberrant nuclear/cytoplasmic expression of } \\
\beta \text {-catenin, more prominent in the morular } \\
\text { component of the tumor } \\
\text { ER } \beta \text { expression in these tumors mimics that } \\
\text { of } \beta \text {-catenin }\end{array}$ & $\begin{array}{l}\beta \text {-catenin expression is membranous } \\
\text { AFP, GPC- } 3 \text {, and SALL- } 4 \text { positivity more } \\
\text { prominent in the non-fetal lung-like compartment }\end{array}$ \\
\hline & No p53 overexpression & Commonly nuclear $\mathrm{p} 53$ overexpression \\
\hline $\begin{array}{l}\text { Low rates of mutations in KRAS, EGFR, and } \\
\text { PIK3CA }\end{array}$ & $\begin{array}{l}\text { Mutations in exon } 3 \text { of } \beta \text {-catenin. Mutations } \\
\text { in these phosphorylation sites interfere } \\
\text { with } \beta \text {-catenin degradation and cause it to } \\
\text { accumulate in the nucleus and cytoplasm } \\
\text { Theoretical mutational inactivation of the APC } \\
\text { or PTEN genes }\end{array}$ & $\begin{array}{l}\text { No mutations in the } \beta \text {-catenin gene } \\
\text { p53 mutations }\end{array}$ \\
\hline
\end{tabular}

Notes: a Diagnosis is rendered when the fetal histology is predominant. 'Lepidic, papillary, acinar, micropapillary, solid patterns, and hepatoid. 'Grade of positivity for neuroendocrine markers (chromogranin A and synaptophysin) for H-FLAC is dependent on the percentage of the fetal lung-like component present in the tumor. ${ }^{d} \mathrm{No}$ mutation present in $\beta$-catenin gene analyses but aberrant nuclear/cytoplasmic expression of $\beta$-catenin seen in immunohistochemistry.

Abbreviations: FLAC, fetal adenocarcinoma of the lung; L-FLAC, low-grade FLAC; H-FLAC, high-grade FLAC; APC, adenomatous polyposis coli; ER $\beta$, estrogen receptor $\beta$; AFP, alfafetoprotein; GPC-3, glypican 3; TTF-I, thyroid transcription factor I.

(chromogranin A and synaptophysin). Initially, positivity was thought to be more prominent in L-FLAC compared to H-FLAC; however, recent studies have shown that the grade of positivity of neuroendocrine markers in H-FLAC is dependent on the percentage of the fetal lung-like component present in the tumor. ${ }^{21,23} \mathrm{~A}$ similar behavior has been described with thyroid transcription factor 1 expression in H-FLAC. ${ }^{14}$ Additionally, L-FLAC has shown an aberrant nuclear/cytoplasmic expression of $\beta$-catenin, a characteristic which is more prominent in the morular component of the tumor with no 553 overexpression. In contrast, $\beta$-catenin expression in H-FLAC is usually membranous and these tumors commonly overexpress p53, resembling traditional lung adenocarcinoma. ${ }^{18,24-29}$ Interestingly, PB shares part of the immunohistochemical profile of both categories of FLAC, since it has aberrant nuclear/cytoplasmic $\beta$-catenin staining, more prominently in the epithelial compartment and also overexpresses p53. ${ }^{26,28-30}$ Alfafetoprotein (AFP), glypican 3, and SALL-4 are also expressed in H-FLAC, with a more prominent expression profile in the non-fetal lung-like component compared to the fetal lung-like component. $^{23}$

\section{Genomics}

Multiple molecular studies have reported very low rates of mutations in KRAS, EGFR, and PIK3CA in FLAC. A mutational analysis performed in a Chinese population identified an L858R point mutation in EGFR in a H-FLAC case and a T790M EGFR mutation in a L-FLAC case. The remaining cases had wild-type $E G F R$ and harbored no other mutations in $K R A S, P I K 3 C A$, or $B R A F .{ }^{18}$ Another study identified an exon 19 deletion and the L858R point mutation of EGFR in one and two cases, respectively, of H-FLAC. E545A point mutation of PIK3CA was also detected in another H-FLAC case. No mutations on KRAS or BRAF were identified in this study. ${ }^{14}$ Morita et $\mathrm{al}^{23}$ reported one case of H-FLAC with an L858R mutation of EGFR and another showed a $K R A S$ mutation in either codon 12 or 13 . The remaining cases tested presented wild-type $E G F R$ and $K R A S$. Conventional lung adenocarcinoma has a mutation frequency of $32 \%-64 \%$ for $E G F R$ and $13 \%$ for $K R A S .{ }^{31-36}$ Given the high mutation frequency for these genes in lung adenocarcinoma in comparison to the low frequency seen in FLAC, several authors have suggested that these tumors may have distinctive molecular features and, because of this, the 
recognition of FLAC as a separate histopathological entity has been debated. ${ }^{14,18,23}$

Other molecular markers have also been implicated in the tumorigenesis of FLAC. The Wnt signaling pathway is important during embryogenesis, but when altered can lead to tumor formation. The Wnt signal causes $\beta$-catenin to translocate to the nucleus, which activates target genes that form complexes with lymphoid enhancer factor/T-cell factor. In normal circumstances, a multi-protein complex (that includes the adenomatous polyposis coli [APC] tumor suppressor protein) degrades excess $\beta$-catenin, hence keeping its levels regulated. Mutational inactivation of APC or direct mutations on $\beta$-catenin that inhibit its degradation will cause nuclear accumulation of the protein. This will lead to the activation of oncogenic target genes such as $c-m y c$ and cyclin D1. ${ }^{37}$ Since the final step in the altered Wnt pathway is the nuclear accumulation of $\beta$-catenin, alterations in this pathway may be detected with direct gene analysis and with immunohistochemistry ${ }^{38}$ Studies have indicated that various morule forming tumors (L-FLAC, cribriform papillary thyroid carcinoma, adenoma of the gall bladder, adenoma of the colon, pancreatoblastoma) express $\beta$-catenin in an aberrant nuclear/ cytoplasmic fashion in the morular formations of the tumor. Estrogen receptor $\beta$ (ER $\beta$ ) expression in these tumors mimics that of $\beta$-catenin. These findings suggest that the morular formation of these tumors is induced by the nuclear/cytoplasmic translocation of $\beta$-catenin and ER $\beta$; whether these two events are related warrants further investigation. ${ }^{24,30,39}$

Initially, Nakatani et al followed by other authors described that L-FLAC consistently showed an aberrant nuclear/cytoplasmic $\beta$-catenin expression. H-FLAC displays a membranous expression of the protein. ${ }^{18,23,27}$ Afterwards, the L-FLAC with aberrant $\beta$-catenin expression was further characterized through gene sequencing. One study identified that all the L-FLAC had somatic missense mutations in exon 3 of $\beta$-catenin that resulted in the substitution of serine/threonine residues at GSK- $3 \beta$ phosphorylation sites or at an amino acid flanking one of these residues..$^{30}$ Other studies showed that most, but not all, L-FLAC had mutations in exon 3 of $\beta$-catenin. Mutations in these phosphorylation sites interfere with $\beta$-catenin degradation and cause it to accumulate in the nucleus and cytoplasm. The author in these studies suggested that the sporadic L-FLAC cases that lacked $\beta$-catenin mutations could have mutational inactivation of the $A P C$ or PTEN tumor suppressor genes; these genetic alterations also lead to an aberrant nuclear/cytoplasmic expression of $\beta$-catenin. ${ }^{25,26}$ All three studies demonstrated that H-FLAC harbored no mutations in the $\beta$-catenin gene. Interestingly, PB with morular formation in the epithelial component has aberrant nuclear/cytoplasmic expression of $\beta$-catenin and mutations in the $\beta$-catenin gene. PB without morules shows no alterations in the Wnt signaling pathway. ${ }^{25,26,30} \beta$-catenin mutations have been reported to be rare in lung cancers; therefore, the high prevalence of these mutations in L-FLAC and $\mathrm{PB}$ with morules is a molecular hallmark and can become a diagnostic tool for these tumors. ${ }^{30,40-43}$

Another molecular distinction between L-FLAC and H-FLAC is p53 mutations. Various studies have confirmed that H-FLAC demonstrates nuclear $\mathrm{p} 53$ overexpression; this pattern is not present in L-FLAC. ${ }^{18,23}$ Besides, Bodner and Koss identified that none of the L-FLAC cases contained p53 gene mutations, while all the PB they studied contained missense mutations in exons 5, 7, and 8. According to this study, p53 mutations are statistically more frequent in PB than in L-FLAC. The frequency of $\mathrm{p} 53$ gene mutations in PB and H-FLAC displays a similar frequency to conventional lung cancer; however, the lack of p53 mutations in L-FLAC cases suggests that favorable prognosis of this tumor may be related to a lesser number of molecular alterations. ${ }^{29}$ H-FLAC appears to be closer to conventional lung cancer; this supports the concept of discriminating between L-FLAC and H-FLAC. ${ }^{25}$

Immunohistochemical and molecular analyses of $\mathrm{p} 53$ and $\beta$-catenin have demonstrated that the epithelial and mesenchymal components of $\mathrm{PB}$ with morules are monoclonal. ${ }^{29,30}$ This finding has led to two different theories about the histogenesis of L-FLAC, H-FLAC, and PB. One theory states that when PB develops, if a $\beta$-catenin mutation occurs early in the process it will lead to L-FLAC, as a one-sided epithelial outgrowth with morule formation. If this mutation does not occur, PB with no morule formation with an abundant mesenchymal component will develop. This would suggest that these entities can be organized into a spectrum where PB with morules is placed between L-FLAC and PB without morules. ${ }^{30}$ In contrast, Nakatani et al suggest that L-FLAC and H-FLAC are histogenetically different tumors. They speculate that the formation of a biphasic pattern present in PB is a later event that arises from either L-FLAC or H-FLAC through the process of epithelial and mesenchymal transition. According to the extent of epithelial-mesenchymal transition, the proportion of the epithelial and mesenchymal components may vary. ${ }^{26}$ Further studies are warranted to solve this debate. Genomic characteristics of L-FLAC and H-FLAC are summarized in Table 1. 


\section{Diagnosis and clinical characteristics}

Approximately $25 \%-40 \%$ of patients present with asymptomatic disease; therefore, most of the cases are diagnosed through incidental findings on chest radiographs. Symptoms are related to bronchial irritation: chest pain is usually the main complaint, cough, hemoptysis, and dyspnea have also been reported. Pleural effusion is uncommon. ${ }^{1,23,44,45} \mathrm{On}$ chest radiographs, FLAC is seen as a peripherally located well-demarcated lesion ranging from 2 to $12 \mathrm{~cm}$ with peripherally placed radiopacities. ${ }^{14,17,22,44,46}$ On computed tomography, these tumors show a heterogeneous appearance with enhancing whorls of soft tissue and non-enhancing areas of necrosis. Metastases to the same or opposite lung, or to the mediastinal compartment may also be apparent. ${ }^{46}$ Patients with H-FLAC may present with elevated serum levels of AFP. ${ }^{21}$ From a pathologic point of view, FLAC is difficult to diagnose preoperatively. Usually the diagnosis is made on postoperative specimens or at autopsy. ${ }^{47}$ Metastases to the ovary, eye, and skin have been described. ${ }^{21,22,48}$

L-FLAC and H-FLAC also show different clinical characteristics. H-FLAC is more common in elderly male patients, around the sixth to seventh decade of life, with a heavy smoking history ( $93 \%$ smoking rate). ${ }^{23,27}$ On the other hand, L-FLAC tends to occur in young females at the third to fourth decade of life. ${ }^{1,2,18,23,44,49,50}$ Patients with L-FLAC usually present with stage I-II disease, while patients with H-FLAC usually present with a more advanced-stage disease (stage III-IV) (Table 2)..$^{21,23,31}$

\section{Treatment}

Due to the fact that PB and FLAC were categorized as two separate entities, studies that evaluate the treatment of this entity in an independent manner are limited. Surgical resection is the standard treatment for PB and FLAC. Radiotherapy and chemotherapy have been used as adjuvant therapy, although in some reports they have shown limited effect. ${ }^{51,52} \mathrm{~A}$ case study reports a patient with T3N0 disease who underwent

Table 2 Clinical characteristics in L-FLAC and H-FLAC

\begin{tabular}{ll}
\hline L-FLAC & H-FLAC \\
\hline Young females at the third to fourth & Elderly male patients, sixth to \\
decade of life & seventh decade of life \\
Present with stage I-II disease & Heavy smoking history \\
& Present with an advanced-stage \\
& disease (III-IV)
\end{tabular}

Abbreviations: L-FLAC, low-grade fetal adenocarcinoma of the lung; H-FLAC, high-grade fetal adenocarcinoma of the lung treatment with three cycles of etoposide-cisplatin protocol. The patient showed a $12 \%$ tumor reduction evaluated through computed tomography. ${ }^{53}$ Another patient with a T4N0M0stage disease treated with neoadjuvant chemotherapy (mitomycin, ifosfamide, and cisplatin) showed a downstage prior to tumor resection..$^{52}$ Kyung et al reported the case of a patient with locally advanced disease that was treated with concurrent chemotherapy with docetaxel; the patient had a partial response. ${ }^{54}$ The combination of surgery, adjuvant radiotherapy, and chemotherapy based on cisplatin and etoposide has been suggested. ${ }^{51}$ A Swiss study used treatment with cisplatin, VP-16, uromitexan, ifosfamide, and 64 Gy or mediastinal radiotherapy on a T3N2M0 patient and reported a 33-month survival. ${ }^{45}$ (A summary of the therapeutic approach can be found in Table 3.)

\section{Outcomes}

Poor prognostic factors for FLAC include thoracic lymphadenopathy, metastasis at diagnosis, and tumor recurrence. Size of the tumor has been debated. ${ }^{17,55}$ Koss et al showed that the median survival for patients with FLAC was not reached at 10 years while that of $\mathrm{PB}$ was of $\sim 1$ year. ${ }^{17}$ Larsen and Sorensen showed a median survival for FLAC of 34 months and for PB of 11 months. ${ }^{56}$ Several studies have shown 10-year survival for FLAC of $75 \%$ and for PB of $15 \%{ }^{2,52,57-59}$ The prognostic studies performed by Kodama et al and Koss et al showed differences in outcomes and survival within all of the FLAC cases. ${ }^{8,17}$ Nakatani et al suggested that the grade of malignancy and the tumor stage explained the differences in prognosis seen in these two studies, and further stated that even though it is not known whether the prognosis of H-FLAC is worse than the stage-matched conventional adenocarcinoma, L-FLAC probably has a better prognosis than the stage-matched conventional pulmonary adenocarcinoma.

Table 3 Therapeutic approach for patients with FLAC

Treatment

- Standard: surgical resection

- Radiotherapy and chemotherapy used as adjuvant therapy have shown limited effect

Poor prognostic factors

- Thoracic lymphadenopathy

- Metastases at diagnosis

- Tumor recurrence

Abbreviation: FLAC, fetal adenocarcinoma of the lung. 


\section{Disclosure}

The authors report no conflicts of interest in this work.

\section{References}

1. Patnayak R, Jena A, Rukmangadha N, Lakshmi AY, Chandra A. Welldifferentiated fetal adenocarcinoma of the lung in an adult male: report of an unusual tumor with a brief review of literature. J Cancer Res Ther. 2014;10(2):419-421.

2. Esper A, Force S, Gal A, Wolfenden LL. A 36-year-old woman with hemoptysis and a lung mass 3 months after delivery. Chest. 2006;130(5):1620-1623.

3. Ou SH, Kawaguchi T, Soo RA, Kitaichi M. Rare subtypes of adenocarcinoma of the lung. Expert Rev Anticancer Ther. 2011;11(10):1535-1542.

4. Barrett NR, Barnard WG. Some unusual thoracic tumours. Br J Surg. 1945;32(128):447-457.

5. Barnard WG. Embryoma of lung. Thorax. 1952;7(4):299-301.

6. Spencer H. Pulmonary blastomas. J Pathol Bacteriol. 1961;82(1): 161-166.

7. Kradin RL, Young RH, Dickersin GR, Kirkham SE, Mark EJ. Pulmonary blastoma with argyrophil cells and lacking sarcomatous features (pulmonary endodermal tumor resembling fetal lung). Am J Surg Pathol. 1982;6(2):165-172.

8. Kodama T, Shimosato Y, Watanabe S, Koide T, Naruke T, Shimase J. Six cases of well-differentiated adenocarcinoma simulating fetal lung tubules in pseudoglandular stage. Comparison with pulmonary blastoma. Am J Surg Pathol. 1984;8(10):735-744.

9. Brambilla E, Travis WD, Colby TV, Corrin B, Shimosato Y. The new World Health Organization classification of lung tumours. Eur Respir J. 2001;18(6):1059-1068.

10. World Health Organization. Histological Typing of Lung and Pleural Tumors. 3rd ed. Geneva: WHO; 1999.

11. Geisinger KR, Travis WD, Perkins LA, Zakowski MF. Aspiration cytomorphology of fetal adenocarcinoma of the lung. Am J Clin Pathol. 2010;134(6):894-902.

12. World Health Organization. WHO Classification of Tumors of the Lung, Pleura, Thymus and Heart. 4th ed. Geneva: WHO; 2011.

13. Longo M, Levra MG, Capelletto E, et al. Fetal adenocarcinoma of the lung in a 25-year-old woman. J Thorac Oncol. 2008;3(4):441-443.

14. Suzuki M, Yazawa T, Ota S, et al. High-grade fetal adenocarcinoma of the lung is a tumour with a fetal phenotype that shows diverse differentiation, including high-grade neuroendocrine carcinoma: a clinicopathological, immunohistochemical and mutational study of 20 cases. Histopathology. 2015;67(6):806-816.

15. Mistry JH, Pawar SB, Mehta H, Popov AF, Mohite PN. Primary pulmonary blastoma of monophasic variety - diagnosis and management. J Cardiothorac Surg. 2013;8:144.

16. Peacock MJ, Whitwell F. Pulmonary blastoma. Thorax. 1976;31(2):197-204.

17. Koss MN, Hochholzer L, O'Leary T. Pulmonary blastomas. Cancer. 1991;67(9):2368-2381.

18. Zhang J, Sun J, Liang X-L, Lu J-L, Luo Y-F, Liang Z-Y. Differences between low and high grade fetal adenocarcinoma of the lung: a clinicopathological and molecular study. JThorac Dis. 2017;9(7):2071-2078.

19. Geisinger KR, Travis WD, Perkins LA, Zakowski MF. Aspiration cytomorphology of fetal adenocarcinoma of the lung. Am J Clin Pathol. 2010;134(6):894-902.

20. Lee KG, Cho NH. Fine-needle aspiration cytology of pulmonary adenocarcinoma of fetal type: report of a case with immunohistochemical and ultrastructural studies. Diagn Cytopathol. 1991;7(4):408-414.

21. Nakatani Y, Kitamura H, Inayama Y, et al. Pulmonary adenocarcinomas of the fetal lung type: a clinicopathologic study indicating differences in histology, epidemiology, and natural history of low-grade and highgrade forms. Am J Surg Pathol. 1998;22(4):399-411.

22. Chao S-C, Lee JY-Y. Well-differentiated fetal adenocarcinoma presenting with cutaneous metastases. Br J Dermatol. 2004;150(4):778-780.
23. Morita S, Yoshida A, Goto A, et al. High-grade lung adenocarcinoma with fetal lung-like morphology: clinicopathologic, immunohistochemical, and molecular analyses of 17 cases. Am J Surg Pathol. 2013;37(6):924-932.

24. Nakatani Y, Masudo K, Nozawa A, et al. Biotin-rich, optically clear nuclei express estrogen receptor-beta: tumors with morules may develop under the influence of estrogen and aberrant beta-catenin expression. Hum Pathol. 2004;35(7):869-874.

25. Nakatani Y, Masudo K, Miyagi Y, et al. Aberrant nuclear localization and gene mutation of beta-catenin in low-grade adenocarcinoma of fetal lung type: up-regulation of the Wnt signaling pathway may be a common denominator for the development of tumors that form morules. Mod Pathol. 2002;15(6):617-624.

26. Nakatani Y, Miyagi Y, Takemura T, et al. Aberrant nuclear/cytoplasmic localization and gene mutation of beta-catenin in classic pulmonary blastoma: beta-catenin immunostaining is useful for distinguishing between classic pulmonary blastoma and a blastomatoid variant of carcinosarcoma. Am J Surg Pathol. 2004;28(7):921-927.

27. Nakatani Y, Dickersin GR, Mark EJ. Pulmonary endodermal tumor resembling fetal lung: a clinicopathologic study of five cases with immunohistochemical and ultrastructural characterization. Hum Pathol. 1990;21(11):1097-1107.

28. Pacinda SJ, Ledet SC, Gondo MM, et al. p53 and MDM2 immunostaining in pulmonary blastomas and bronchogenic carcinomas. Hum Pathol. 1996;27(6):542-546.

29. Bodner SM, Koss MN. Mutations in the p53 gene in pulmonary blastomas: immunohistochemical and molecular studies. Hum Pathol. 1996;27(11):1117-1123.

30. Sekine S, Shibata T, Matsuno Y, et al. Beta-catenin mutations in pulmonary blastomas: association with morule formation. $J$ Pathol. 2003;200(2):214-221.

31. Zhang J, Liang Z, Gao J, Luo Y, Liu T. Pulmonary adenocarcinoma with a micropapillary pattern: a clinicopathological, immunophenotypic and molecular analysis. Histopathology. 2011;59(6):1204-1214.

32. Kosaka T, Yatabe Y, Onozato R, Kuwano H, Mitsudomi T. Prognostic implication of EGFR, KRAS, and TP53 gene mutations in a large cohort of Japanese patients with surgically treated lung adenocarcinoma. J Thorac Oncol. 2009;4(1):22-29.

33. Mitsudomi T, Kosaka T, Endoh H, et al. Mutations of the epidermal growth factor receptor gene predict prolonged survival after gefitinib treatment in patients with non-small-cell lung cancer with postoperative recurrence. J Clin Oncol. 2005;23(11):2513-2520.

34. Broët P, Dalmasso C, Tan EH, et al. Genomic profiles specific to patient ethnicity in lung adenocarcinoma. Clin Cancer Res. 2011;17(11):3542-3550.

35. Haneda H, Sasaki H, Lindeman N, et al. A correlation between EGFR gene mutation status and bronchioloalveolar carcinoma features in Japanese patients with adenocarcinoma. Jpn J Clin Oncol. 2006;36(2):69-75.

36. Song Z, Zhu H, Guo Z, Wu W, Sun W, Zhang Y. Correlation of EGFR mutation and predominant histologic subtype according to the new lung adenocarcinoma classification in Chinese patients. Med Oncol. 2013;30(3):645.

37. Behrens J. Control of beta-catenin signaling in tumor development. Ann NY Acad Sci. 2000;910:21-33; discussion 33-35.

38. Brabletz T, Jung A, Hermann K, Günther K, Hohenberger W, Kirchner T. Nuclear overexpression of the oncoprotein beta-catenin in colorectal cancer is localized predominantly at the invasion front. Pathol Res Pract. 1998;194(10):701-704.

39. Makishi S, Kinjo T, Sawada S, et al. Morules and morule-like features associated with carcinomas in various organs: report with immunohistochemical and molecular studies. J Clin Pathol. 2006;59(1): 95-100.

40. Shigemitsu K, Sekido Y, Usami N, et al. Genetic alteration of the beta-catenin gene (CTNNB1) in human lung cancer and malignant mesothelioma and identification of a new $3 \mathrm{p} 21.3$ homozygous deletion. Oncogene. 2001;20(31):4249-4257. 
41. Sunaga N, Kohno T, Kolligs FT, Fearon ER, Saito R, Yokota J. Constitutive activation of the Wnt signaling pathway by CTNNB1 (betacatenin) mutations in a subset of human lung adenocarcinoma. Genes Chromosomes Cancer. 2001;30(3):316-321.

42. Ueda M, Gemmill RM, West J, et al. Mutations of the beta- and gammacatenin genes are uncommon in human lung, breast, kidney, cervical and ovarian carcinomas. Br J Cancer. 2001;85(1):64-68.

43. Hommura F, Furuuchi K, Yamazaki K, et al. Increased expression of beta-catenin predicts better prognosis in nonsmall cell lung carcinomas. Cancer. 2002;94(3):752-758.

44. Sato S, Koike T, Yamato Y, Yoshiya K, Honma K, Tsukada H. Resected well-differentiated fetal pulmonary adenocarcinoma and summary of 25 cases reported in Japan. Jpn J Thorac Cardiovasc Surg. 2006;54(12):539-542.

45. Robert J, Pache J-C, Seium Y, de Perrot M, Spiliopoulos A. Pulmonary blastoma: report of five cases and identification of clinical features suggestive of the disease. Eur J Cardiothorac Surg. 2002;22(5):708-711.

46. Hansell D, Lynch D, McAdams HP, Bankier A. Imaging of Diseases of the Chest. 5th ed. Amsterdam: Elsevier; 2010. Available from: https://www.elsevier.com/books/imaging-of-diseases-of-the-chest/ hansell/978-0-7234-3496-2. Accessed February 28, 2018.

47. Kohno H, Baba M, Fujisawa T, et al. Pulmonary blastoma: report of a case. Surg Today. 1999;29(8):803-806.

48. Huysentruyt CJ, Vandevijver NM, van Suylen R, Van de Vijver K. Adenocarcinoma of the fetal lung-type metastatic to the ovary. Int $J$ Gynecol Pathol. 2010;29(4):339-340.

49. Cherian SV, Akasapu K, Kumar A, Mauzo SH, Bhattacharjee MB. A 34-year-old pregnant woman with cough, chest pain, and a left upper lobe mass. Chest. 2016;150(3):e87-e91.
50. Politiek MJ, Vrugt B, Aalbers R. A 49-year-old woman with welldifferentiated fetal adenocarcinoma. Neth J Med. 2001;58(4):177-180.

51. Cutler CS, Michel RP, Yassa M, Langleben A. Pulmonary blastoma: case report of a patient with a 7-year remission and review of chemotherapy experience in the world literature. Cancer. 1998;82(3):462-467.

52. Zaidi A, Zamvar V, Macbeth F, Gibbs AR, Kulatilake N, Butchart EG. Pulmonary blastoma: medium-term results from a regional center. Ann Thorac Surg. 2002;73(5):1572-1575.

53. Lkhoyaali S, Boutayeb S, Ismaili N, et al. Neoadjuvant chemotherapy in well-differentiated fetal adenocarcinoma: a case report. $B M C$ Res Notes. 2014;7:283.

54. Kyung C, Kim SY, Lim BJ, et al. A case of locally advanced welldifferentiated fetal adenocarcinoma of the lung treated with concurrent chemoradiation therapy. Tuberc Respir Dis. 2013;74(5):226-230.

55. Novotny JE, Huiras CM. Resection and adjuvant chemotherapy of pulmonary blastoma. A case report. Cancer. 1995;76(9):1537-1539.

56. Larsen H, Sorensen JB. Pulmonary blastoma: a review with special emphasis on prognosis and treatment. Cancer Treat Rev. 1996;22(3):145-160.

57. Sheehan KM, Curran J, Kay EW, Broe P, Grace A. Well differentiated fetal adenocarcinoma of the lung in a 29 year old woman. J Clin Pathol. 2003;56(6):478-479.

58. Mardini G, Pai U, Chavez AM, Tomashefski JF. Endobronchial adenocarcinoma with endometrioid features and prominent neuroendocrine differentiation. A variant of fetal adenocarcinoma. Cancer. 1994;73(5):1383-1389.

59. Vaideeswar P, Agarwal AP. Foetal adenocarcinoma of the lung. J Postgrad Med. 2004;50(1):75-76.
Lung Cancer: Targets and Therapy

\section{Publish your work in this journal}

Lung Cancer: Targets and Therapy is an international, peer-reviewed, open access journal focusing on lung cancer research, identification of therapeutic targets and the optimal use of preventative and integrated treatment interventions to achieve improved outcomes, enhanced survival and quality of life for the cancer patient. Specific topics covered in the journal include: Epidemiology, detection and screening Cellular research and biomarkers; Identification of biotargets and agents with novel

Submit your manuscript here: https://www.dovepress.com/lung-cancer-targets--therapy-journa
Dovepress

mechanisms of action; Optimal clinical use of existing anticancer agents, including combination therapies; Radiation and surgery; Palliative care; Patient adherence, quality of life, satisfaction; Health economic evaluations. The manuscript management system is completely online and includes a very quick and fair peer-review system. Visit http://www.dovepress.com/testimonials.php to read real quotes from published authors. 